\title{
FORMULATION EVALUATION AND OPTIMIZATION OF ORODISPERSIBLE TABLETS OF PANTOPRAZOLE SODIUM BY THE USING OF DIFFERENT SUPERDISINTEGRANTS
}

\author{
LOKENDRA SINGH CHUNDAWAT*, VISHAL SHARMA
}

Department of Pharmaceutics, Mandsaur University Mandsaur,Mandsaur, Madhya Pradesh, India. Email: chundawatlokendra@gmail.com Received: 03 January 2018, Revised and Accepted: 17 January 2018

\author{
ABSTRACT \\ Objective: The objective of this study was to formulate and optimize an orodispersible formulation of pantoprazole sodium using a $3^{2}$ factorial design \\ for optimized the superdisintegrant concentration.
}

Methods: Various concentrations (2\%, 4\%, and 6\%) of superdisintegrants (sodium starch glycollate [SSG] and crospovidone [CP]) were added in the formulation, all processing steps are carried out at a temperature below 250c and relative humidity $<35 \%$. Procedure to manufacture orodispersible tablets by direct compression was established.

Results: The results show that the presence of a superdisintegrants is desirable for orodispersion. The best-optimized batch found was the batch having amount of CP $4.37 \mathrm{mg}$ and SSG $10.59 \mathrm{mg}$. All the formulations satisfied the limits of orodispersion with a dispersion time of <30 s best formulation showed a disintegration time (DT) of $30 \mathrm{~s}$, \% friability is $0.82 \%$, drug content of $96-99.4$, and fast drug release rate of $80 \%$ of drug release within $10 \mathrm{~min}$.

Conclusion: The optimized batch was evaluated for thickness, weight variation, hardness, friability, DT dissolution, and accelerated stability study for a period of 3 months. The similarity factor was calculated for comparison of dissolution profile before and after stability studies. The $\mathrm{f}^{2}$ value was found more than 50 that indicate a good similarity between both the dissolution profiles. Hence, the results of stability studies reveal that the developed formulation has good stability.

Keywords: Pantoprazole sodium, Orodispersion, Crospovidone, Sodium starch glycollate, Factorial design, Tablet properties.

(C) 2018 The Authors. Published by Innovare Academic Sciences Pvt Ltd. This is an open access article under the CC BY license (http://creativecommons. org/licenses/by/4. 0/) DOI: http://dx.doi.org/10.22159/ajpcr.2018.v11i5.24595

\section{INTRODUCTION}

Difficulty in swallowing is a common problem of all age groups, especially geriatric and pediatric patients, due to physiological changes associated with these groups. These problems can be solved by the development of a novel type of solid dosage form, namely, orodispersible tablet, which disintegrates and dissolves rapidly in saliva without the need of swallowing with drinking water since the tablet is placed in the mouth where it disperses rapidly before swallowing [1,2].

Pantoprazole is a potent and selective proton pump inhibitor. It is an effective agent in the treatment of peptic ulcers, gastroesophageal reflux disease, esophagitis, Zollinger-Ellison syndrome, and other gastrointestinal hypersecretory disorders. It provides rapid symptoms relief up to $85-90 \%$ of ulcer patients within $1 \mathrm{~h}$ of treatment. It has a mediocre bioavailability of $50 \%$ and poor aqueous solubility and thus makes its absorption and dissolution rate limited, delaying its onset of action to a certain extent. Pantoprazole is available as a conventional tablet in the market, and many patients find it difficult to swallow these, especially pediatric and geriatric subjects which result in high incidence of non-compliance and ineffective therapy. In this present study, an effort has been made to formulate fast disintegrating and rapid release tablets, also called as OraSolv tablets, of pantoprazole using two different superdisintegrants, namely, crospovidone (CP) and sodium starch glycollate (SSG) by direct compression method. Evaluation of the tablets showed that all the tablets were found to be within official limits and the disintegration time (DT) for the formulations ranged from $15 \mathrm{~s}$ to $25 \mathrm{~s}$. The formulated orally disintegrating tablets (ODT's) have potential advantages over conventional marketed tablets with their improved patient compliance, both in geriatrics and pediatrics, ease of administration, and bioavailability [3].
In this present study, an effort has been made to formulate fast disintegrating and rapid release tablets of pantoprazole using two different superdisintegrants, namely, CP and SSG [4] by direct compression method. The objective of this study was to enhance the safety and efficacy of the drug molecule, achieve better patient compliance, solve the problem of difficulty in swallowing, enhance onset of action and provide a stable dosage form [5].

\section{EXPERIMENTAL}

\section{Materials}

Pantoprazole sodium was a kind gift from Vasudha Pharma Ltd. (Andhra Pradesh, India), CP and SSG were purchased from Signet Chemical Corporation, Mumbai. Lactose and Mannitol were from Micro Labs (Hosur). Microcrystalline cellulose, aspartame was purchased from S.D. Fine Chemicals (Mumbai). Methanol and Water (HPLC Grade) were purchased from Merck (India). All other chemicals and reagents were of analytical grade.

\section{Methods \\ Experimental design}

Using $3^{2}$ full factorial design [6], the optimization of independent factors (amount of superdisintegrant 1 - CP and amount of superdisintegrant 2 - SSG) was done. DT and friability factors were represented as dependent factors.

Code X1 is given for the amount of superdisintegrant 1 (CP), and Code $\mathrm{X} 2$ is given for the amount of superdisintegrant 2 (SSG) (Tables 1-3).

\section{Formulation Orodispersible tablets}

Pantoprazole orodispersible tablet was prepared by direct compression method [7]. 
The most common and simplest method available for tablet compression is direct compression in which the drug with other excipients is mixed thoroughly with the help of various mixers followed by the compression of the resulting powder. Using capsule shape punch in modified rotary compression machine (16 stations) by Cadmach CMD 3-16.

\section{Evaluation of Orodispersible tablets}

\section{Hardness}

Tablets require a certain amount of strength, or hardness, to withstand the mechanical shocks of handling in manufacturing, packaging as well as in shipping. The hardness of the tablets here was measured using a simple Monsanto hardness tester.

\section{Friability}

The friability of the tablets was determined using Roche friabilator. It is expressed in percentage (\%). 10 tablets were initially weighed and transferred into the friabilator. The friabilator was operated at $25 \mathrm{rpm}$ for $4 \mathrm{~min}$ [8]. After $4 \mathrm{~min}$ the tablets were weighed again. The friability was then calculated using the formula:

Friability $(\%)=\frac{\text { Initial weight-Final Weight }}{\text { Initial weight }} \times 100$

\section{Weight variation test}

Twenty tablets were randomly selected from each batch and individually weighed. The average weight and standard deviation of 20 tablets were calculated.

Table 1: $3^{2}$ Full factorial design layout

\begin{tabular}{lll}
\hline Batch code & Factor $\mathbf{1}$ & Factor 2 \\
& X1 & X2 \\
\hline$A_{1}$ & -1 & -1 \\
$A_{2}$ & -1 & 0 \\
$A_{3}$ & -1 & 1 \\
$A_{4}$ & 0 & -1 \\
$A_{5}$ & 0 & 0 \\
$A_{6}$ & 0 & 1 \\
$A_{7}$ & 1 & -1 \\
$A_{8}$ & 1 & 0 \\
$A_{9}$ & 1 & 1 \\
\hline
\end{tabular}

Assay

A total of 20 tablets from each batch were weighed and powdered.20 mg of pantoprazole sodium equivalent to pantoprazole was weighed and dissolved in ethanol; the solution was filtered and made the volume up to $50 \mathrm{ml}$ with distilled water into the volumetric flask. [9]

Absorbance was measured at $289 \mathrm{~nm}$ using Shimadzu UV spectrophotometer and percent purity was determined.

\section{In vitro drug release}

Measure the absorbance of standard preparation and sample preparation in $1 \mathrm{~cm}$ cell on a suitable spectrophotometer at $289 \mathrm{~nm}$, using dissolution medium as a blank. Calculate the quantity as a percentage of drug dissolved using following formula:

Drug $\times(\mathrm{mg} / \mathrm{tab})=\mathrm{AT} / \mathrm{AS} \times \mathrm{WS} / 100 \times 5 / 50 \times \mathrm{P} / 100 \times 100$

Where,

AT=Absorbance of test solution

AS $=$ Absorbance of standard solution

WS=Weight of working standard taken in $\mathrm{mg}$

$\mathrm{P}=$ Percentage purity of working standard (on as is basis)

\section{Stability study}

The ICH Guidelines have established that long-term stability testing should be done at $25^{\circ} \mathrm{C} / 60 \% \mathrm{RH}$; stress testing should be done at $40^{\circ} \mathrm{C} / 75 \%$ RH for 6 months. If a significant change occurs at these stress condition, then the formulation should be tested at an intermediate condition, i.e., $30^{\circ} \mathrm{C} / 65 \%$ RH (Table 4 ).

\section{RESULTS AND DISCUSSION}

The tablets were evaluated for different parameters and were within limits of weight variation, hardness, and drug content. Friability of the tablets was found to decrease with an increase in the concentration of both factors. MCC increases friability. CP is also known to produce mechanically strong tablets. Thus, both the factors had desired effects on DT and friability. These effects were further analyzed using statistical models.

According to the European Pharmacopoeia [10,11], the fast disintegrating/orodispersible tablets should disintegrate within $3 \mathrm{~min}$ without leaving any residue on the screen increase in the levels of CP

Table 2: Coded values for X1 and X2

\begin{tabular}{|c|c|c|}
\hline Coded value & $\begin{array}{l}\text { Amount of superdisintegrant } 1 \text { (CP) in } \mathrm{mg} \\
\mathrm{X} 1\end{array}$ & $\begin{array}{l}\text { Amount of superdisintegrant } 2 \text { (SSG) in - } 1 \mathrm{mg} \\
\mathrm{X} 2\end{array}$ \\
\hline-1 & 3.6 & 7.2 \\
\hline 0 & 5.4 & 9 \\
\hline 1 & 7.2 & 10.8 \\
\hline
\end{tabular}

SSG: Sodium starch glycollate, CP: Crospovidone

Table 3: Formulation using $3^{2}$ full factorial designs

\begin{tabular}{|c|c|c|c|c|c|c|c|c|c|}
\hline Ingredients & F1 (mg) & F2 (mg) & F3 (mg) & F4 (mg) & F5 (mg) & F6 (mg) & F7 (mg) & F8 (mg) & F9 (mg) \\
\hline Drug & 23 & 23 & 23 & 23 & 23 & 23 & 23 & 23 & 23 \\
\hline Mgo & 23 & 23 & 23 & 23 & 23 & 23 & 23 & 23 & 23 \\
\hline Ethyl cellulose & 2 & 2 & 2 & 2 & 2 & 2 & 2 & 2 & 2 \\
\hline $\mathrm{CP}$ & 3.6 & 5.4 & 7.2 & 3.6 & 5.4 & 7.2 & 3.6 & 5.4 & 7.2 \\
\hline SSG & 7.2 & 7.2 & 7.2 & 9 & 9 & 9 & 10.8 & 10.8 & 10.8 \\
\hline MCC & 27 & 27 & 27 & 27 & 27 & 27 & 27 & 27 & 27 \\
\hline Mannitol & 32.5 & 32.5 & 32.5 & 32.5 & 32.5 & 32.5 & 32.5 & 32.5 & 32.5 \\
\hline Aspartame & 9 & 9 & 9 & 9 & 9 & 9 & 9 & 9 & 9 \\
\hline Talc & 1.5 & 1.5 & 1.5 & 1.5 & 1.5 & 1.5 & 1.5 & 1.5 & 1.5 \\
\hline Mg starate & 3 & 3 & 3 & 3 & 3 & 3 & 3 & 3 & 3 \\
\hline Flavor & q.s & q.s & q.s & q.s & q.s & q.s & q.s & q.s & q.s \\
\hline Total weight (mg) & 180 & 180 & 180 & 180 & 180 & 180 & 180 & 180 & 180 \\
\hline
\end{tabular}

SSG: Sodium starch glycollate, CP: Crospovidone 
and SSG had a negative effect on DT, i.e., DT decreased with increase in the levels of both factors. CP is known for rapid disintegration activity due to fast water wicking action. The disintegrating time was found to be between $18 \mathrm{~s}$ and $94 \mathrm{~s}$. Optimum effect is shown in following concentration range CP: $2-4 \%$ and SSG: 4-6\%.

Dissolution studies

ODT should release not $<80 \%$ of the stated amount of drug the dissolution profiles of all 9 trial batches showed more than $80 \%$ of drug release within $10 \mathrm{~min}$. It was observed that there was not much

Table 4: ICH guide lines for stability study

\begin{tabular}{lll}
\hline Study & Storage condition & Time period \\
\hline Long-term* & $25^{\circ} \mathrm{C} \pm 2{ }^{\circ} \mathrm{C} / 60 \% \mathrm{RH} \pm 5 \% \mathrm{RH}$ & 12 months \\
& $30^{\circ} \mathrm{C} \pm 2{ }^{\circ} \mathrm{C} / 65 \% \mathrm{RH} \pm 5 \% \mathrm{RH}$ & \\
Intermediate** & $30^{\circ} \mathrm{C} \pm 2{ }^{\circ} \mathrm{C} / 65 \% \mathrm{RH} \pm 5 \% \mathrm{RH}$ & 6 months \\
Accelerated & $40^{\circ} \mathrm{C} \pm 2{ }^{\circ} \mathrm{C} / 75 \% \mathrm{RH} \pm 5 \% \mathrm{RH}$ & 6 months \\
\hline${ }^{*}$ Whether long-term stability studies are performed at $25{ }^{\circ} \mathrm{C} \pm 2{ }^{\circ} \mathrm{C} / 60 \% \mathrm{RH}$ \\
$\pm 5 \% \mathrm{RH}$ or $30^{\circ} \mathrm{C} \pm 2{ }^{\circ} \mathrm{C} / 65 \% \mathrm{RH} \pm 5 \% \mathrm{RH}$ or $30{ }^{\circ} \mathrm{C} \pm 2{ }^{\circ} \mathrm{C} / 75 \% \mathrm{RH} \pm 5 \% \mathrm{RH}$ \\
is determined by the climatic condition under which the $\mathrm{API}$ is intended to be \\
stored (see Appendix 1 ). Testing at a more severe long-term condition can be an \\
alternative to testing condition, i.e. $25^{\circ} \mathrm{C} / 60 \% \mathrm{RH}$ or $30{ }^{\circ} \mathrm{C} / 65 \% \mathrm{RH}$. \\
${ }^{* *}$ If $30^{\circ} \mathrm{C} \pm 2{ }^{\circ} \mathrm{C} / 65 \% \mathrm{RH} \pm 5 \% \mathrm{RH}$ or $30{ }^{\circ} \mathrm{C} \pm 2{ }^{\circ} \mathrm{C} / 75 \% \mathrm{RH} \pm 5 \% \mathrm{RH}$ is the \\
long-term condition there is no intermediate condition.
\end{tabular}

variation in dissolution profiles among the tablet formulation and the factors under study had no effect on the drug release (Tables 5 and 6, Figs. 1 and 2).

\section{Optimization of tablets}

Design layout for optimization (Table 7)

Tablets were optimized using a different combination of factor X1 and X2.Design layouts for optimization were given in Table 7

\section{Statistical analysis of response}

Statistical analysis is performed by multiple regression analysis using software Design Expert 8.0.7.1.

Nine batches were prepared, and polynomial equation [12] was derived for the desired response. Contour plots were prepared for the dependent variable. Derived equation is validated by preparing a checkpoint batch.

Factorial equation for response 1: Disintegration time

$\mathrm{R} 1=+26.62-5.67 * \mathrm{~A}-9.33 * \mathrm{~B}-2.00 * \mathrm{~A} * \mathrm{~B}+1.83 * \mathrm{~A} 2+10.83 * \mathrm{~B} 2$

Where, $\mathrm{R} 1=$ Disintegration time

Result obtained from factorial design is explained below

Table 5: Optimization of prepared batches

\begin{tabular}{|c|c|c|c|c|c|c|c|}
\hline $\begin{array}{l}\text { Batch } \\
\text { code }\end{array}$ & Thickness* (mm) & Avg weight* (mg) & Hardness* $\left(\mathrm{kg} / \mathrm{cm}^{2}\right)$ & Friability* (\%) & $\begin{array}{l}\text { Disintegration } \\
\text { time* }^{*}(s)\end{array}$ & $\begin{array}{l}\text { \%Drug } \\
\text { content* }\end{array}$ & $\begin{array}{l}\text { \%Drug } \\
\text { release* }\end{array}$ \\
\hline A1 & $2.11 \pm 0.12$ & $179.6 \pm 0.70$ & $4.09 \pm 0.13$ & $0.71 \pm 0.89$ & $54 \pm 0.11$ & $98.84 \pm 0.86$ & $95.48 \pm 9.45$ \\
\hline $\mathrm{A} 2$ & $1.96 \pm 0.12$ & $180.8 \pm 1.17$ & $3.86 \pm 0.12$ & $0.76 \pm 0.74$ & $42 \pm 0.69$ & $99.76 \pm 0.34$ & $97.29 \pm 3.72$ \\
\hline A3 & $2.08 \pm 0.16$ & $181.1 \pm 0.57$ & $3.88 \pm 0.19$ & $0.70 \pm 1.43$ & $48 \pm 0.44$ & $96.11 \pm 0.3$ & $92.13 \pm 2.81$ \\
\hline A4 & $1.99 \pm 0.02$ & $179.6 \pm 2.18$ & $3.64 \pm 0.17$ & $0.77 \pm 1.51$ & $32 \pm 0.12$ & $98.67 \pm 0.21$ & $91.61 \pm 3.72$ \\
\hline A5 & $2.12 \pm 0.03$ & $181.6 \pm 1.11$ & $3.48 \pm 0.11$ & $0.79 \pm 0.93$ & $28 \pm 0.71$ & $97.68 \pm 0.72$ & $99.27 \pm 3.73$ \\
\hline A6 & $2.02 \pm 0.12$ & $180.4 \pm 0.91$ & $3.52 \pm 0.10$ & $0.86 \pm 1.07$ & $18 \pm 0.92$ & $98.38 \pm 0.29$ & $97.80 \pm 3.72$ \\
\hline A8 & $2.08 \pm 0.16$ & $180.5 \pm 2.59$ & $3.64 \pm 0.16$ & $0.82 \pm 0.81$ & $26 \pm 0.14$ & $96.41 \pm 0.11$ & $97.51 \pm 9.45$ \\
\hline A9 & $2.03 \pm 0.11$ & $182.8 \pm 0.54$ & $3.54 \pm 0.13$ & $0.81 \pm 0.97$ & $24 \pm 0.36$ & $99.91 \pm 0.21$ & $97.51 \pm 9.45$ \\
\hline
\end{tabular}

*The values represent mean \pm standard deviation, $\mathrm{n}=5$

Table 6: Dissolution data of formulation A1 to A9\% drug release in $900 \mathrm{ml} 6.8$ phosphate buffer $50 \mathrm{rpm}, 37^{\circ} \mathrm{C} \pm 0.1^{\circ} \mathrm{C}, \mathrm{USP}$ Type II

\begin{tabular}{|c|c|c|c|c|c|c|c|c|c|}
\hline Time & A1 & A2 & A3 & A4 & A5 & A6 & A7 & A8 & A9 \\
\hline 0 & 0 & 0 & 0 & 0 & 0 & 0 & 0 & 0 & 0 \\
\hline 1 & 18.12 & 28.34 & 23.12 & 30.85 & 35.26 & 46.19 & 18.9 & 26.3 & 39.23 \\
\hline 2 & 31.67 & 40.8 & 36.67 & 43.92 & 52.75 & 59.57 & 42.25 & 48.59 & 54.49 \\
\hline 4 & 50.31 & 53.49 & 56.31 & 56.34 & 69.08 & 73.92 & 62.31 & 65.82 & 69.96 \\
\hline 6 & 68.36 & 68.36 & 74.36 & 70.05 & 82.23 & 84.71 & 74.35 & 75.56 & 78.56 \\
\hline 8 & 79.95 & 82.95 & 88.95 & 83.27 & 91.15 & 93.94 & 83.26 & 84.95 & 86.54 \\
\hline 10 & 91.48 & 93.29 & 92.13 & 94.61 & 99.27 & 97.8 & 95.1 & 97.51 & 95.51 \\
\hline
\end{tabular}

Table 7: Response data for $3^{2}$ Full factorial optimization design

\begin{tabular}{|c|c|c|c|c|}
\hline \multirow[t]{2}{*}{ Batch code } & $\begin{array}{l}\text { Factor } 1 \\
\text { X1 }\end{array}$ & $\begin{array}{l}\text { Factor } 2 \\
\text { X2 }\end{array}$ & Response 1 & Response 2 \\
\hline & Amount of CP (mg) & Amount of SSG (mg) & Disintegration time (s) & $\%$ Friability \\
\hline$A_{1}$ & 5.4 & 9 & 28 & 0.79 \\
\hline$A_{2}$ & 7.2 & 10.8 & 24 & 0.81 \\
\hline $\mathrm{A}_{3}^{2}$ & 5.4 & 10.8 & 26 & 0.82 \\
\hline $\mathrm{A}_{4}^{3}$ & 7.2 & 9 & 18 & 0.86 \\
\hline$A_{5}^{4}$ & 7.2 & 7.2 & 48 & 0.70 \\
\hline$A_{6}^{5}$ & 3.6 & 9 & 32 & 0.77 \\
\hline$A_{7}^{6}$ & 3.6 & 7.2 & 54 & 0.71 \\
\hline $\mathrm{A}_{8}^{\prime}$ & 3.6 & 10.8 & 38 & 0.76 \\
\hline$A_{9}^{8}$ & 5.4 & 7.2 & 42 & 0.76 \\
\hline
\end{tabular}

SSG: Sodium starch glycollate, CP: Crospovidone 
The model $\mathrm{F}$ value of 10.40 implies the model is significant. There is only a $0.39 \%$ chance that a "Model F value" this large could occur due to noise. Values of $p<0.0500$ indicate model terms are significant. Values $>0.1000$ indicate the model terms are not significant. $p$ values for A, B, A2, and B2 were found to be 0.0019, 0.0288, 0.0392, and 0.0031 which is $<0.05$, thus the significant effect on dependent variable $\mathrm{R} 1$, $\mathrm{p}$ value for term $\mathrm{AB}$ was found to be 0.3428 which is $>0.05$, thus non-significant effect on R1. The R2 (0.9363) was high indicating the adequate fitting of quadratic model. The polynomial equation can also be used to draw the conclusion considering the magnitude of coefficient and the mathematical sign it carries, i.e., +ve or -ve. -ve sign of variable indicates that as the concentration of superdisintegrants increase DT decreases (Table 8).

\section{Factorial equation for response 2: Friability}

$\mathrm{R}_{2}=+0.78+0.022 * \mathrm{~A}+0.037 * \mathrm{~B}$

Where,

$\mathrm{R}_{2}=$ Friability

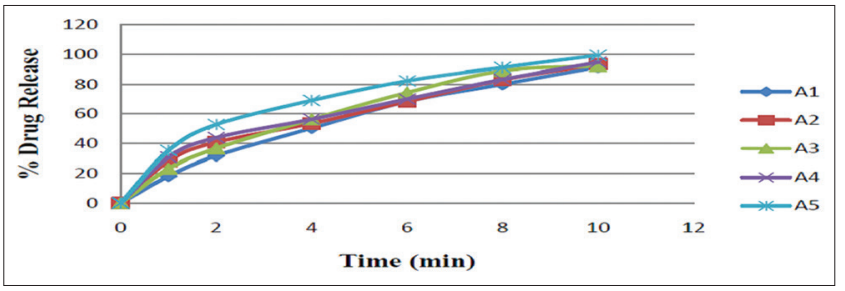

Fig. 1: Comparative dissolution profile of $A_{1}$ to $A_{5}$

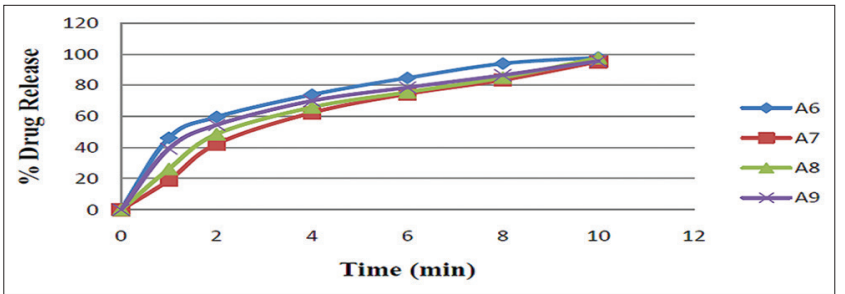

Fig. 2: Comparative dissolution profile of $A_{6}$ to $A 9$
Result obtained from factorial design is explained below

The model $\mathrm{F}$ value of $5.08 \mathrm{implies}$ the model is significant. There is only a $3.01 \%$ chance that a "model $\mathrm{F}$ value" this large could occur due to noise. $\mathrm{p}<0.0500$ indicate model terms are significant. In this case, B is significant model terms. Values $>0.1000$ indicate the model terms are not significant. $p$ values for $B$ were found to be 0.0207 , which is $<0.05$, thus significant effect on dependent variable R2. $p$ value for term $A$ was found to be 0.1360 which is $>0.05$, thus non-significant effect on R1. The R2 (0.9363) was high indicating the adequate fitting of quadratic model. The polynomial equation can also be used to draw the conclusion considering the magnitude of coefficient and the mathematical sign it carries, i.e., +ve or -ve. +ve sign of variable indicates that as the concentration of superdisintegrants increase friability also increases.

Construction of response surface plots (Figs. 3 and 4)

\section{Overlay plot}

The optimization of the formulation was carried out from overlay plot. Overlay plot gives the area of interest or area of the experiment. In Fig. 5, yellow region reflects the area of experiment (Fig. 5).

\section{Check point batch}

To confirm the equation generated by multiple regression analysis, checkpoint batch is prepared. The values of all possible combinations of two independent factors A and B were derived from contour plots, and data were filtered using excel software. A value for optimized formulation was obtained from overlay plot. It is called as checkpoint batch (Table 9).

Formulation of checkpoint batch $\mathrm{C}$ is given in table number 9

\section{Validation of mathematical model}

From the polynomial equation and contour plots, the best-optimized batch found was the batch having the amount of CP $4.37 \mathrm{mg}$ and SSG $10.59 \mathrm{mg}$. Checkpoint batch was prepared for model validation.

The response DT and friability were evaluated and found within limits. The values of response predicted from the model analysis shown in Table 10. The close resemblance between the observed and the predicted response value assessed the robustness of prediction. These values indicate the validity of the generated model.

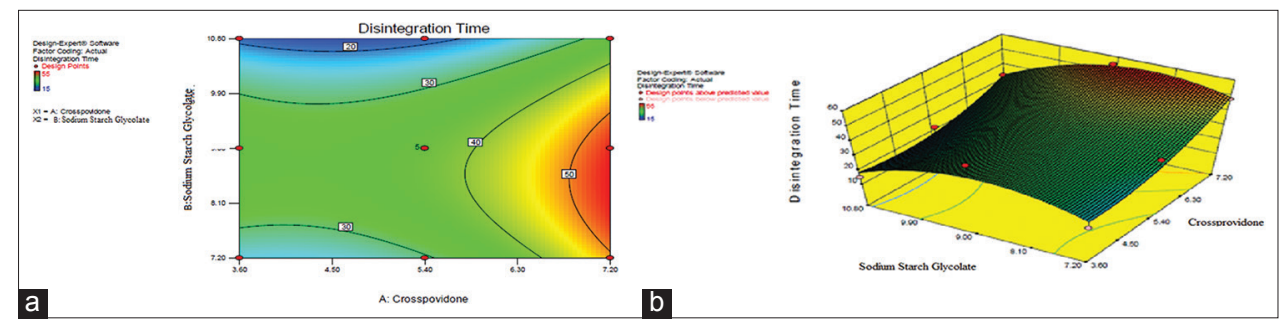

Fig. 3: Diagrammatic representation of (a) contour plot and (b) 3D view of effect of A and B on disintegration time

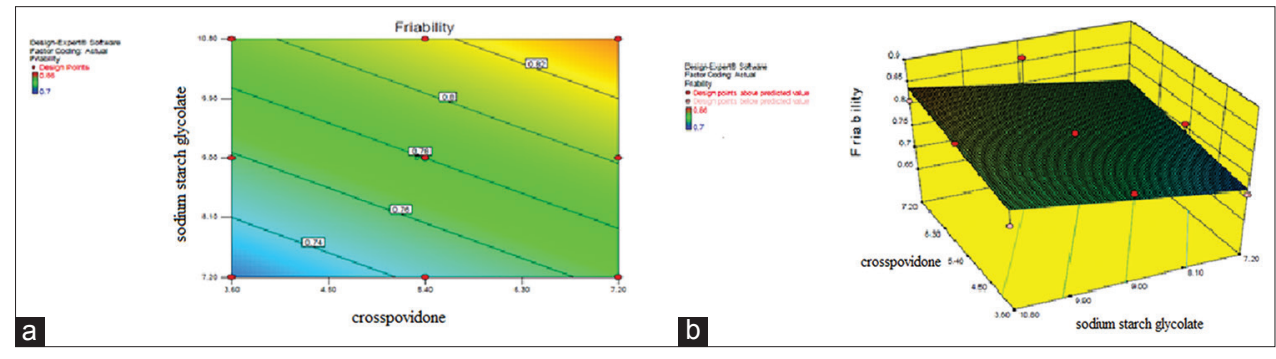

Fig. 4: Diagrammatic representation of (a) contour plot and (b) 3D view of effect of $A$ and $B$ on friability 
The similarity factor was calculated for comparison of dissolution profile before and after stability studies. The $\mathrm{f}^{2}$ value was found more than 50 that indicate a good similarity between both the dissolution profiles. Similarly, no significant difference was observed in the DT after stability studies. Hence, the results of stability studies reveal that the developed formulation has good stability (Fig. 6 and Table 11).

\section{CONCLUSION}

The ODTs have potential advantages over conventional oral dosage forms as they improved patient compliance; Convenience, rapid onset of action and bioavailability .The present study developed Orodispersible tablet

Table 8: Regression output of R1 for $3^{2}$ full factorial design

\begin{tabular}{llll}
\hline Parameter & Value & Parameter & Value \\
\hline Sum of square & 1255.75 & Mean \pm SD & $34.31 \pm 4.91$ \\
Degree of freedom & 5 & C.V \% & 10.39 \\
Mean square & 251.15 & $\mathrm{R}^{2}$ & 0.9363 \\
Model F value & 10.40 & p value & 0.0039 \\
\hline
\end{tabular}

SD: Standard deviation

\begin{tabular}{llll}
\hline Parameter & Value & Parameter & Value \\
\hline Sum of square & 0.011 & Mean \pm SD & $0.78 \pm 0.033$ \\
Degree of freedom & 2 & C.V \% & 4.2 \\
Mean square & $5.442 \mathrm{E}-003$ & $\mathrm{R}^{2}$ & 0.5039 \\
Model F value & 5.08 & $\mathrm{p}$ value & 0.0301 \\
\hline
\end{tabular}

SD: Standard deviation

Table 9: Formulation of checkpoint batch - C

\begin{tabular}{ll}
\hline Ingredient & Quantity taken (mg) \\
\hline Drug & 23 \\
MgO & 23 \\
Ethyl cellulose & 2 \\
CP & 4.37 \\
SSG & 10.59 \\
MCC & 27 \\
Mannitol & 32.5 \\
Lactose & 44.04 \\
Aspartame & 9.0 \\
Talc & 1.5 \\
Mg stearate & 3.0 \\
Flavor & q.S \\
Total weight (mg) & 180 \\
\hline
\end{tabular}

SSG: Sodium starch glycollate, CP: Crospovidone

Table 10: Validation of mathematical model

\begin{tabular}{lllll}
\hline $\begin{array}{l}\text { Batch } \\
\text { code }\end{array}$ & $\begin{array}{l}\text { Dependent } \\
\text { variable }\end{array}$ & $\begin{array}{l}\text { Predicted } \\
\text { value }\end{array}$ & $\begin{array}{l}\text { Observed } \\
\text { value }\end{array}$ & \% error \\
\hline C & $\begin{array}{l}\text { Disintegration } \\
\text { time (s) } \\
\text { \% friability }\end{array}$ & $20 \mathrm{~s}$ & 21.25 & $6.25 \%$ \\
& $0.8 \%$ & $0.82 \%$ & $2.5 \%$ \\
\hline
\end{tabular}

which is soluble in saliva are absorbed from the mouth, pharynx, and oesophagus as the saliva passes down into the stomach, thus enhance the bioavailability by avoiding first pass metabolism. Various concentrations $(2 \%, 4 \%$, and $6 \%)$ of superdisintegrants (SSG, CP) were added in the formulation, all processing steps are carried out at a temperature below $250 \mathrm{c}$ and relative humidity $<35 \%$. Procedure to manufacture orodispersible tablets by direct compression was established.

Developed ODT gave satisfactory results for various physicochemical evaluations such as hardness, friability, weight variation, drug content, and in vitro DT and in vitro dissolution profiles. DT and \% friability of ODT depends on the concentration of superdisintegrants. The DT and $\%$ friability of all the formulation varied from $81 \pm 1.37$ to $18 \pm 0.92 \mathrm{~s}$ and $0.87 \pm 1.95$ to $0.70 \pm 1.43$. Combination of superdisintegrants is used to derive the satisfactory result. The concentration of superdisintegrants was optimized using $3^{2}$ full factorial design with the help of design expert 8.0.7.1 version software, in that two independent factors were a concentration of CP (2-4\%) and concentration of SSG (4-6\%). Three different levels were coded as $(-1,0,+1)$. From the polynomial equation and contour plots, the best-optimized batch found. Checkpoint batch was prepared for model validation. The close resemblance between the observed and the predicted response value assessed the robustness of prediction. These values indicate the validity of the generated model.

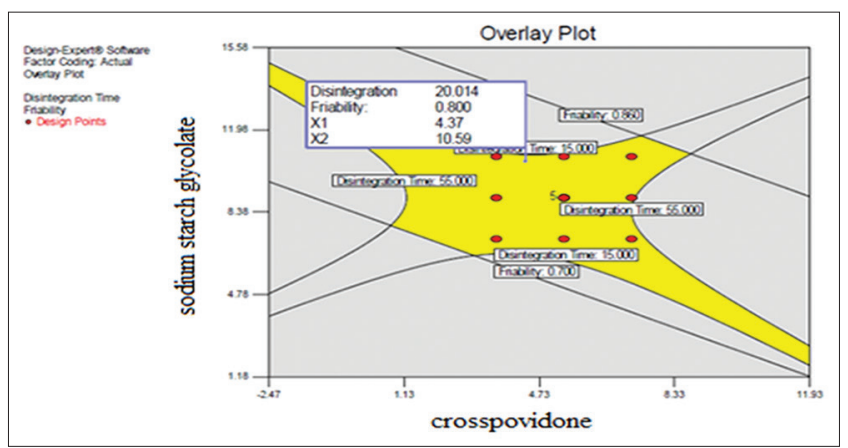

Fig. 5: Overlay plot

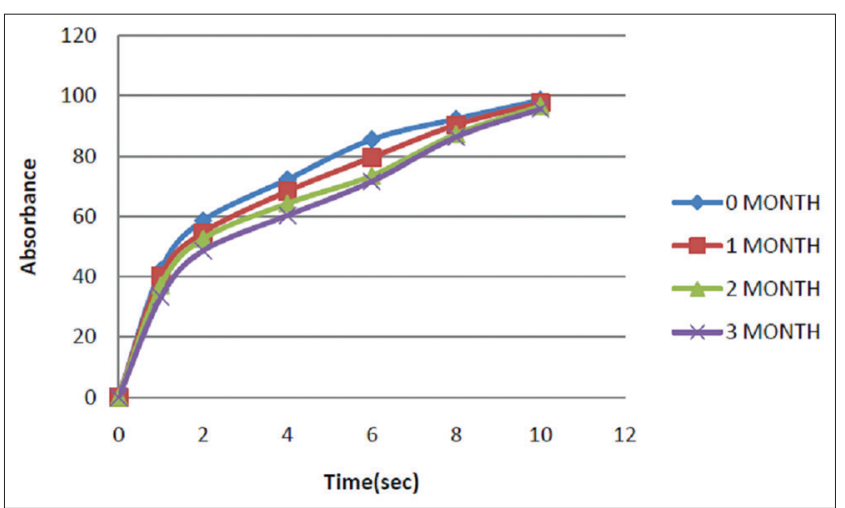

Fig. 6: Comparisons of release profile of stability batch at accelerated stability study

Table 11: Stability study evaluation data

\begin{tabular}{|c|c|c|c|c|c|}
\hline Sr.no. & Evaluation Parameter & 0 month & 1 month & 2 months & 3 months \\
\hline 1 & Appearance & White & White & White & White \\
\hline 2 & Hardness & $3.76 \pm 0.17$ & $3.76 \pm 0.17$ & $3.76 \pm 0.17$ & $3.76 \pm 0.17$ \\
\hline 3 & Disintegration time & $22 \pm 0.19$ & $22 \pm 0.54$ & $24 \pm 0.92$ & $26 \pm 0.38$ \\
\hline 4 & \% Friability & $0.81 \pm 3.89$ & $0.81 \pm 2.67$ & $0.79 \pm 2.18$ & $0.78 \pm 1.86$ \\
\hline 5 & $\%$ Drug content & $98.43 \pm 0.62$ & $98.07 \pm 0.28$ & $97.48 \pm 0.21$ & $96.76 \pm 0.42$ \\
\hline 6 & \% Drug release & $98.88 \pm 2.46$ & $97.65 \pm 3.32$ & $95 \pm 1.97$ & $93.37 \pm 2.81$ \\
\hline 7 & $\mathrm{f}^{2}$ value & 94.82 & 96.05 & 95.48 & 96.27 \\
\hline
\end{tabular}


The optimized batch was evaluated for thickness, weight variation, hardness, friability, DT dissolution, and accelerated stability study for a period of 3 months. The similarity factor was calculated for comparison of dissolution profile before and after stability studies. The $\mathrm{f}^{2}$ value was found more than 50 that indicate a good similarity between both the dissolution profiles. Hence, the results of stability studies reveal that the developed formulation has good stability. This work needs to be proved more effective by its bioavailability, pre-clinical, and clinical studies further studies are needed to investigate these formulations for its performance in vivo. The result of the study indicates that orodispersible tablet of Pantoprazole sodium that can be successfully prepared. Undoubtedly, the availability of various technologies and the manifold advantages of ODT will surely enhance the patient compliance and its popularity in the near future.

\section{CONFLICTS OF INTEREST}

The author declares there is no conflict of interest.

\section{REFERENCES}

1. Nilesh PT, Nitin SB, Ganesan V, Raju T, Durgesh RD. Orodispersible tablets of lansoprazole. Int J Chem Tech Res 2010;1:400-5.
2. Kumaresan C. Orally disintegrating tablet-rapid disintegration, sweet taste, and target release profile. Pharm Rev 2008;6:434-8.

3. Paul W. Junnickel pantoprazole: A new proton pump inhibitor. Clin Ther 2000;22:1268-93.

4. Rowe RC, Sheskey PJ, Owen SC. Hand Book of Pharmaceutical Excipients. $5^{\text {th }}$ ed. Great Britan: Pharmaceutical Press; 2006. p. 22-704.

5. International Specialty Products. Pharmaceutical Technical Bulletin; 1994. Available from: http://www.ispcorp.com.

6. Bolton S. Pharmaceutical statistics. In: Drug and the Pharmaceutical Sciences. New York, USA: Marcel Decker Inc.; 1997. p. 326-38.

7. Indian Pharmacopoeia. Appendices. $4^{\text {th }}$ ed. Vol. II. New Delhi: Controller of Publications; 1996. p. 7-8.

8. Controller of Publications. Indian Pharmacopoeia. $4^{\text {th }}$ ed. Vol. II. New Delhi: Controller of Publications; 1996. p. 234-6.

9. Controller of Publications. Indian Pharmacopoeia. 4th ed. Vol. II. New Delhi: Controller of Publications; 1996. p. 735-6.

10. Bi Y, Akinobu O. Evaluation of a compressed tablet rapidly disintegrating in the oral cavity. Chem Pharm Bull 1995;44:2011-7.

11. Directorate of Medicine and Health. European Pharmacopoeia. $5^{\text {th }}$ ed., Vol. I. Great Britain: Directorate of Medicine and Health; 2005. p. 628-9.

12. Bolton S. Pharmaceutical Statistics In: Drug and the Pharmaceutical Sciences. New York, USA: Marcel Decker Inc.; 1997. p. 345-51. 